\title{
Analisis Ritual Perang Pandan Berbasis Perspektif Diakronis di Desa Wisata Tenganan Pegringsingan
}

I Komang Agus Moni Artadia,1 Saptono Nugroho a,2

1moni_artadi@yahoo.co.id 2saptono_nugroho@unud.ac.id

a Program Studi Sarjana Destinasi Pariwisata, Fakultas Pariwisata, Universitas Udayana, Jl. Dr. R. Goris, Denpasar, Bali 80232 Indonesia

\section{Abstract}

Tenganan Pegringsingan Village Tourism is located in Karangasem Regency, which has many ancestral cultures and traditions that are still held today. One of the famous traditions of the Tenganan Pegringsingan Village Tourism is the tradition perang pandan (Mekare - kare). Perang pandan has its own uniqueness that can only be found in Tenganan Village, from this uniqueness that makes many tourists who visit the Tenganan Pegringsingan Village Tourism just to witness the uniqueness of the perang pandan ritual.

This study sought to find diachronic developments in the implementation of the perang pandan ritual, before and after the establishment of Tenganan Pegringsingan Village into a Village Tourism, using the over-time comparative method. The results of this study indicate, first seen from the indicator of time, participants who followed the tradition of the perang pandan ritual experienced a change. Secondly seen from the room indicator, the implementation of the perang pandan ritual is still permanent, cannot be changed. Third, judging from the level indicator, the perang pandan ritual has begun to move to a more complex level than before. and the last seen from the composite indicator, time, space and level, the perang pandan ritual has begun to be packaged into a tourist attraction, in the form of a festival tenganan that is routinely carried out every year.

Keywords: Perang pandan, Diachronic Perspective. Village Tourism

\section{PENDAHULUAN}

Kabupaten Karangasem merupakan salah satu Kabupaten yang berada di Provinsi Bali yang menyimpan banyak potensi wisata, mulai dari potensi alam, budaya berserta buatan. Salah satu Daya Tarik Wisata yang terkenal di Kabupaten Karangasem adalah Desa Wisata Tenganan Pegringsingan, pada era pemerintahan Soekarno di Tahun 1960, Desa Wisata Tenganan Pegringsingan sudah ditetapkan secara resmi sebagai daerah tujuan wisata budaya. Desa Wisata Tenganan Pegringsingan. Terletak di Kecamatan Manggis, 5 kilometer sebelum kawasan pariwisata Candidasa. Desa Wisata Tenganan Pegringsingan merupakan satu dari sekian banyak Desa Wisata di Bali yang memiliki keunikan tersendiri, Desa Wisata merupakan sebagian atau keseluruhan wilayah desa yang memiliki potensi, produk dan aktivitas wisata yang dimanfaatkan untuk pengembangan pariwisata dan dikelola oleh kelompok masyarakat di Desa secara berkelanjutan (Suryawan,2016).

Desa Wisata Tenganan yang lebih dikenal dengan Tenganan Pegringsingan merupakan salah satu desa tua/kuno yang terdapat di pulau Bali, pola kehidupan masyarakat Desa Tenganan yang mencerminkan kebudayaan dan adat istiadat Desa Bali Aga (pra- Hindu) yang berbeda dari desa - desa lain di bali Desa Wisata Tenganan Pegringsigan menyimpan banyak tradisi yang diwarisi secara turun temurun, yang tetap dilestarikan hingga saat ini, Desa Wisata Tenganan Pegringsingan memiliki banyak keunikan diantaranya adalah sistem kemasyarakatannya yang menganut sistem perkawinan parental dimana perempuan dan laki - laki memiliki hak yang sama sebagai ahli waris, menerapkan sistem endogami dan yang sangat terkenal di Desa Wisata Tenganan Pegringsingatn yaitu Ritual Perang Pandan (Mekare-kare).

Ritual perang pandan atau (Mekare kare) merupakan tradisi yang masih dipertahankan oleh masyarakat Desa Tenganan, perang pandan (mekare - kare) merupakan suatu tarian yang menggunkan pandan berduri sebagai sarana dalam pelaksanaannya, yang dilakukan dengan menggosokkan pandan berduri pada punggung lawan. Ritual ini khusus ditarikan oleh kaum laki - laki, yang sebelumnya sudah menjalankan ritual (matruna nyoman). Masyarakat Tenganan percaya bahwa darah yang mengalir dari tubuh penari merupakan simbol persembahan suci kepada Dewa Indra (Dewa Perang).

Keunikan adat tradisi perang pandan (mekare - kare), serta gaya hidup masyarakat Desa Tenganan telah menjadi atraksi wisata yang sangat menarik wisatawan, sehingga memberikan dampak positif bagi kegiatan wisata di Desa Wisata Tenganan Pegringsingan, terbukti di tengah dunia yang mengglobal, ritual 
perang pandan (makare - kare) secara tidak langsung menjadi bagian upacara pariwisata dunia.

Dalam pariwisata, perkembangan menjadi hal yang menarik untuk dikaji yang sebenarnya sangat berbeda dengan pengembangan. Perkembangan pariwisata atau turismemorfosis menekankan kepada faktorfaktor perubahan pariwisata pada suatu destinasi wisata, sehingga melalui turismemorfosis sebagai perkembangan pariwisata akan mampu memberikan pemahaman bahwa pariwisata bersifat dinamis (Anom,dkk,2012).

Melalui perkembangan pariwisata terkait dengan perang pandan di Tenganan diharapkan akan memberikan pemahaman untuk keberlangsungan seni budaya dalam pariwisata Seiring berjalannya waktu, pada satu sisi masyarakat Desa Wisata Tenganan Pegringsingan sangat kuat menjaga adat tradisi, teguh menjaga budaya, disisi lain pula menjadi arus perubahan dunia yang disebabkan oleh kegiatan wisata, termasuk ritual perang pandan (mekare - kare). Tujuan dari penelitian ini bermaksud untuk mengetahui Ritual Perang Pandan berbasis perspektif diakronis di Desa Wisata Tenganan Pegringsingan.

\section{KEPUSTAKAAN}

\subsection{Tinjauan Penelitian Sebelumnya}

Penelitian ini mengambil acuan dari beberapa jurnal yang terkait dengan penelitian ini, acuan jurnal yang pertama adalah penelitian yang dilakukan oleh I Nyoman Puja dkk tahun 2016. Penelitian ini didapatkan hasil bahwa Desa Tenganan banyak memiliki potensi wisata, mulai dari wisata budaya, hingga potensi kerajinan tangan seperti kerajian ate dan kain gringsing. Potensi yang dimiliki oleh masyarakat dapat dikembangkan menjadi kegiatan pariwisata dengan memberdayakan potensi masyarakat menjadi pariwisata budaya di Desa Tenganan. Penelitian ini memiliki kesamaan lokus penelitian yang akan dilakukan, sedangkan perbedaan penelitian ini dengan penelitian sebelumnya terletak pada fokus penelitian.

Acuan kedua adalah penelitian yang dilakukan oleh Erfa Arya Putra tahun 2018. Pada penelitian ini di dapatkan hasil bahwa tari barong yang dipentaskan di sanggar - sanggar di Desa Batubulan, bukan menggunakan barong yang sakral, melainkan menggunakan barong tiruan yang difungsikan sebagai tourist art yang dikemas untuk dipertunjukan kepada wisatawan. Kesamaan penelitian ini terletak pada fokus penelitian yang sama - sama mengangkat budaya tradisional masyarakat Bali yang masuk ke ranah pariwisata, sedangkan perbedaanya terletak pada budaya yang diangkat serta lokus penelitian.

\subsection{Tinjauan Konsep \\ 2.2.1 Konsep Diakronis}

Diakronis merupakan golongan yang berpijak pada gejala perkembangan sebagai dokrin pokok, tujuannya untuk mencari pengertian tentang sejarah perkembangan suatu fenomena, suatu unsur atau suatu daerah, yang dapat dilihat melalui empat indikator diantaraknya Waktu, Ruang, Tingkat, serta Gabungan dari Waktu, Ruang dan Tingkat (Geriya 1982).

\subsubsection{Konsep Komodifikasi}

Komodifikasi adalah mengkemas atau mereproduksi kebudayaan menjadi komoditas, Sehingga kebudayaan memasuki ranah ekonomi dan sudah dinilai dengan uang. Dalam hal ini terjadi transformasi penilaian terhadap budaya (Kongres Kebudayaan 2008).

\subsubsection{Konsep Budaya Tradisional}

Budaya Tradisional merupakan sebuah tradisi yang didalamnya terdapat sebuah karya, gaya, konvensi dan kepercayaan yang dipresentasikan sebagai lanjutan dari masa lalu ke masa kini (Pilang 2006).

\section{METODE PENELITIAN}

Penelitian ini berlokasi di Desa Wisata Tenganan Pegringsingan, Kecamatan Manggis, Karangasem, yang karakteristik kawasan lebih di dominasi oleh perbukitan.

Jenis data dalam penelitian ini menggunakan data kualitatif dan data kuantitatif (Sugiyono. 2008:11).

Teknik pengumpulan data dalam penelitian ini menggunakan teknik observasi (Bungi,2007). Kemudian peneliti melakukan wawancara (Bungin, 2007)

Sumber data yang digunakan dalam penelitian ini adalah data primer dan data sekunder (Sugiyono,2008).

Teknik analisis data dalam penelitian ini menggunakan teknik analisis komparasi overtime, komparasi over-time merupakan teknik 
analisis data dengan membandingkan periode yang lama dengan yang baru (Bungin, 2007)

\section{HASIL DAN PEMBAHASAN}

Berdasarkan hasil penelitian dilapangan dapat diperoleh hasil berupa matriks mengenai perkembangan ritual perang pandan dari tahun 2008 sampai 2018 di Desa Wisata Tenganan Pegringsingan

\subsection{Perkembangan Ritual Perang Pandan dari Tahun 2008 - 2018 Menurut Waktu}

Ritual perang pandan (Mekare kare) di Desa Wisata Tenganan Pegringsingan dari tahun 2008 - 2018 dilihat dari perkembangan waktu pelaksanaan dan perserta yang ikut berpartisifasi, terdapat perkembangan yang mendasar dari peserta yang ikut berpartisipasi dalam pelaksanaan ritual perang pandan, jika di tahun 2008 peserta yang ikut berpartiisifasi dalam pelaksanaan ritual perang pandan hanya masayarakat lokal dan beberapa desa - desa yang diundang, namun di tahun 2018 tidak hanya masyarakat lokal dan undangan saja yang terlibat akan tetapi banyak wisatawan mancanegara maupun wisatawan nusantara yang ikut berpartisifasi dalam pelaksanaan ritual perang pandan di Desa Wisata Tenganan Pegringsinga walaupun tidak diundang untuk ikut berpartisifasi.

\subsection{Perkembangan Ritual Perang Pandan dari Tahun 2008 - 2018 Menurut Ruang}

Dilihat dari sudut pandang perkembangan ruang, ritual perang pandan di Desa Wisata Tenganan Pegringsingan tidak terdapat perkembangan ruang yang begitu terlihat. Pelaksanaan ritual perang pandan masih tetap dilaksanakan di tempat dimana ritual Perang pandan tersebut di pentaskan dari dulu, terdapat 2 titikk pementasan ritual perang pandan yaitu di bale (Petemu Kaje) dan di bale (Petemu Tengah).

\subsection{Perkembangan Ritual Perang Pandan dari Tahun 2008 - 2018 menurut Tingkat}

Seiring masuknya kegiatan
pariwisata di Desa Wisata Tenganan Pegringsingan, memberikan dampak terhadap pelaksanaan ritual perang pandan. Ritual perang pandan yang mengalami perkembangan dari tingkat sederhana menjadi lebih tinggi atau kompleks dari tingkat sebelumnya, jika di tahun 2008 pelaksanaan ritual perang pandan masih dilaksanakan di tanah tanpa adanya sarana dan prasarana pendukung, terkecuali alat - alat yang digunakan dalam pelaksanaan ritual perang pandan, namun di tahun 2018 mengingat bahwa banyak wisatawan yang berminat untuk menyaksikan ritual perang pandan, mulai mengalami perkembangan yang dapat dilihat dari terdapatnya panggung untuk pelaksanaan ritual, yang bertujuan untuk memudahkan wisatawan untuk menyaksikan pelaksanaan ritual perang pandan di Desa Wisata Tenganan Pengringsingan.

\subsection{Perkembangan Ritual Perang Pandan dari Tahun 2008 - 2018 Menurut Gabungan, Waktu, Ruang dan Tingkat}

Ritual perang pandan seiring berjalanya waktu terus mengalami perkembangan. Perkembangan dapat dilihat jika ditahun 2008, ritual perang pandan yang masih sederhana dann belum mengarah untuk dikemas menjadi sebuat atraksi wisata di Desa Wisata Tenganan Pegringsingan, namun berbeda di tahun 2018, Ritual perang pandan mengalami peningkan yaitu dapat dilihat dari sudah mulai masuk ke dunia pariwisata, yang dikemas menjadi atraksi wisata dalam bentuk Tenganan Festival yang rutin di selenggarakan di Desa Wisata Tenganan Pegringsingan yang bertepatan dengan pelaksanaan ritual perang pandan.

Tabel 4.1

Matriks Analisis Perkembangan Ritual Perang Pandan

di Desa Wisata Tenganan Pegringsingan

\begin{tabular}{|c|c|c|c|}
\hline No & Waktu & $\begin{array}{c}\text { Tahun } \\
2008\end{array}$ & $\begin{array}{r}\text { Tahun } \\
2018\end{array}$ \\
\hline 1 & Waktu & $\begin{array}{l}\text { Hanya } \\
\text { masyarakat } \\
\text { lokal dan } \\
\text { beberapa Desa } \\
\text { undangan Yang } \\
\text { terlibat dalam } \\
\text { ritual perang } \\
\text { pandan di Desa }\end{array}$ & $\begin{array}{l}\text { Wisatawan } \\
\text { Mancanegara } \\
\text { maupun } \\
\text { Wisatawan } \\
\text { Nusantara } \\
\text { mulai ikut } \\
\text { berpartisifasi } \\
\text { dalam }\end{array}$ \\
\hline
\end{tabular}




\begin{tabular}{|c|c|c|c|}
\hline & & $\begin{array}{l}\text { Wisata } \\
\text { Tenganan } \\
\text { Pegringsingan. }\end{array}$ & $\begin{array}{l}\text { pelaksanaan } \\
\text { ritual perang } \\
\text { pandan } \\
\text { walaupun tidak } \\
\text { di Undang. }\end{array}$ \\
\hline 2 & Ruang & $\begin{array}{l}\text { Pelaksanaan } \\
\text { ritual perang } \\
\text { pandan di Desa } \\
\text { Wisata } \\
\text { Tenganan } \\
\text { Pegringsingan }\end{array}$ & $\begin{array}{l}\text { Pelaksanaan } \\
\text { ritual perang } \\
\text { pandan di Desa } \\
\text { Wisata } \\
\text { Tenganan } \\
\text { Pegringsingan }\end{array}$ \\
\hline 3 & Tingkat & $\begin{array}{l}\text { Ritual perang } \\
\text { pandan masih } \\
\text { sederhana }\end{array}$ & $\begin{array}{l}\text { Ritual perang } \\
\text { pandan sudah } \\
\text { mengarah ke } \\
\text { tingkat lebih } \\
\text { tinggi atau } \\
\text { kompleks }\end{array}$ \\
\hline 4 & $\begin{array}{l}\text { Gabungan } \\
\text { Waktu, } \\
\text { Ruang dan } \\
\text { Tingkat }\end{array}$ & $\begin{array}{l}\text { Masih sangat } \\
\text { sederhana, dan } \\
\text { belum } \\
\text { mengarah } \\
\text { untuk menjadi } \\
\text { sebuah atraksi } \\
\text { wisata }\end{array}$ & $\begin{array}{l}\text { Ritual perang } \\
\text { pandan mulai } \\
\text { menjadi atraksi } \\
\text { wisata yang } \\
\text { dikemas dalam } \\
\text { bentuk festival } \\
\text { tenganan }\end{array}$ \\
\hline
\end{tabular}

Sumber, Penelitian Lapangan 2018

Perkembangan ritual perang pandan yang setiap tahun mengalami perubahan yang mengarah kearah yang lebih komplek. Berkembangnya dunia pariwisata di Desa Wisata Tenganan Pegringsingan berimbas pula pada tradisi ritual perang pandan yang sedikit demi sedikit telah mengalami kesakralannya, jika dahulu ritual perang pandan hanya ditampilkan pada saat upacara besar di Desa Tenganan, namun semenjak masuknya dunia pariwisata, ritual perang pandan mulai ditampilkan untuk wisatawan bahkan wisatawan boleh untuk mengikuti tradisi ritual perang pandan.

Perkembangan pariwisata di Desa Wisata Tenganan Pegringsingan memberikan dampak positif maupun negative pada ritual perang pandan. Perlu upaya yang dilakukan untuk melestarikan ritual perang pandan di Desa Wisata Tenganan Pegringsingan supaya tidak mengarah jauh dari nilai - nilai yang sudah tertanam dalam ritual perang pandan.

Upaya yang paling tepat dilakukan adalah dengan tidak terlalu mengeksploitasi budaya secara berlebihan, serta mempertahankan pakem pakem serta nilai kesakralan tradisi dari ritual perang pandan itu sendiri, hal tersebut tiada lain bertujuan untuk melestarikan budaya leluhur, tradisi, serta budaya masyarakat lokal di Desa Wisata Tenganan Pengringsingan.

Eksploitasi budaya yang berlebihan dari tahun ke tahun akan memberikan dampak yang buruk terhadap ritual perang pandan. Perubahan nilai di dalam ritual perang pandan akan mengurangi pula makna yang terkadung, perlu kesadaran dari masyarakat lokal untuk menjaga tradisi ritual perang pandan supaya tidak mengarah jauh dari nilai yang terkandung sebelumnya, masyarakat lokal memiliki peran yang sangat penting dalam menjaga tradisi ritual perang pandan, hal tersebut dikarenakan masyarakat lokal adalah kunci dari kelestarian tradisi ritual perang pandan.

Upaya untuk menjaga tradisi ritual perang pandan dari masyarakat lokal di Desa Wisata Tenganan Pegringsingan, niscaya akan memberikan dampak positif dalam pelestarian budaya terutama nilai kesakralan dari ritual perang pandan serta keberlangsungan kegiatan pariwisata di Desa Wisata Tenganan Pegringsingan.

\section{PENUTUP}

\subsection{Kesimpulan}

Adapun hasil dari analisis perkembangan ritual perang pandan di Desa Wisata Tenganan Pegringsingan dapat disimpulkan bahwa, Desa Wisata Tenganan Pegringsingan merupakan salah satu desa wisata yang berlokasi di Kecamatan Manggis, Karangasem, yang sangat terkenal dengan budaya yang masih sangat dilestari, salah satunya adalah ritual perang pandan.

Masuknya dunia pariwisata di Desa Wisata Tenganan Pegringsingan sangat berpengaruh terhadap perkembangam ritual perang pandan, yang dilihat dari segi waktu, ruang, tingkat dan gabungan dari waktu,ruang dan tingkat. Dari segi waktu, ditahun 2008 pelaksanaan ritual perang pandan hanya melibatkan masyarakat lokal beserta Desa undangan, di tahun 2018, pelaksanaan ritual perang pandan mulai melibatkan wisatawan mancanegara maupun domestik. Namun dari segi ruang tidak terdapat perkembangan, masih sama yaitu pelaksanaanya hanya di Desa Wisata 
Tenganan Pegringsingan. Dilihat dari segi tingkat di tahun 2008 ritual perang pandan masih sederhana, sementara ditahun 2018 ritual perang pandan sudah mengarah ke tingkat lebih tinggi, dan jika dilihat dari segi gabungan, waktu, ruang dan tingkat, ditahun 2008 ritual perang pandan belum mengarah menjadi atraksi wisata, berbeda dengan tahun 2018, ritual perang pandan sudah menjadi atraksi wisata yang dikemas dalam bentuk tenganan festival.

\subsection{Saran}

Adapun saran yang dapat diberikan terkait dengan analisis ritual perang pandan berbasisi perspektif diakronis adalah Pemerintah yaitu selalu memperhatikan dan menghargai warisan budaya leluhur dan tidak memanfaatkan secara berlebihan sehingga tidak merusak nilai yang terkandung dalam ritual perang pandan.

Selain hal itu pemerintah juga melakukan promosi berkala ke wisatawan sehingga ritual perang pandan lebih dikenal oleh wisatawan. Masyarakat lokal juga harus menjaga budaya leluhur jangan sampai terjadi perubahan perubahan terhadap ritual perang pandan, hal tersebut bertujuan untuk membuat ritual perang pandan tetap hidup dan lestari dalam kehidupan berbudaya masayarat lokal di Desa Wisata Tenganan Pegringsingan.

\section{DAFTAR PUSTAKA}

Anom, I, P., Suryasih, I,A., Nugroho, S., \& Mahagangga, I, G, A, 0. Turis Memorfosis : Tahapan Selama Seratus Tahun Perkembangan Dan Prediksi Pariwisata Bali. Journal of Bali Studies,7(2),59-80

Bungin, Burhan. 2007. Penelitian Kualitatif Komunikasi, Ekonomi Kebijakan Publik dan Ilmu Sosial Lainya. Jakarta: Prenada Media Group.
Geriya, I. M. 1982. Teori Antropologi Diakronis. Jurusan Antropologi Universitas Udayana. Denpasar.

Kongres Kebudayaan . 2008. Definisi Komodifikasi.

Pilang. 2006. Definisi Budaya Tradisional.

Puja, I Nyoman., dkk. 2016. Pemberdayaan Potensi Masyarakat Dalam Pengembangan Pariwisata Budaya di Desa Tenganan Kecamatan Manggis Kabupaten Karangasem Bali.

Putra, Erfa Arya. 2018. Tari Barong dan Pariwisata (Analisis Pementasan Tari Barong di Desa Batubulan Sebagai Daerah Kunjungan Wisatawan. Universitas Udayana. Denpasar.

Rupa, I, Wayan., dkk. 2006. Inventarisasi Karya Buday Mekare Kare Di Desa Tenganan Pegringsingan Kabupaten Karangasem - Bali. Yogyakarta

Sugiyono.2008. "Metode Penelitian Kuantitatif Kualitatif dan $R \& D$ ". Bandung: Alfabeta

Suryawan, Ida Bagus., Suryasih, Ida Ayu., dkk. 2006. Buku Perkembangan Pengembangan Desa Wisata. Bogor: Herya Widia. 